\title{
DIRIGISMO JUDICIAL NOS CONTRATOS EDUCACIONAIS: LIMITES E CRITÉRIOS À INTERVENÇÃO ESTATAL NO PREÇO DAS MENSALIDADES ESCOLARES.
}

\author{
Marcelo Farina de Medeiros
}

Universidade do Oeste Paulista - UNOESTE, Presidente Prudente, SP. E-mail: $\underline{\text { mfmedeiros@unoeste.br }}$

\begin{abstract}
RESUMO
Com a organização normativa amparada em uma Constituição Federal analítica, contendo normas gerais e abstratas que reclamam do julgador uma participação ativa na realização do Direito, no caso concreto, abriu-se espaço ao ativismo judicial. Em relação à teoria do negócio jurídico, a formulação de novos paradigmas, como equidade, boa fé e função social autoriza a intervenção estatal nas relações privadas, visando ao equilíbrio das relações sociais, em especial nos contratos de adesão, em relações de consumo. A intervenção estatal, contudo, encontra barreiras nos princípios constitucionais da livre iniciativa e da propriedade privada. O artigo, portanto, adotando o método dedutivo, visa a contribuir com as ponderações sobre a possibilidade de intervenção estatal nos contratos educacionais privados, conciliando o modelo capitalista adotado na ordem econômica e as garantias a ele inerentes com a defesa do consumidor, sem que isso importe em afronta aos limites da Constituição Federal. Para tanto se faz necessária a aplicação da técnica da ponderação dos direitos constitucionais em conflito, sugerindo a não intervenção estatal na fixação do preço privado, mas em revisão contratual para fins de facilitação de pagamento.
\end{abstract}

Palavras chave: Livre iniciativa. Defesa do consumidor. Contrato educacional.

\section{JUDICIAL INTERVENTIONISM IN EDUCATIONAL CONTRACTS: LIMITS AND REQUIREMENTS FOR THE STATE INTERVENTIONS IN THE PRIVATE SCHOOL PRICES.}

\begin{abstract}
Since the normative organization supported by an analytical Federal Constitution, containing general and abstract norms that claim the judges to active participation in the realization of justice, in specifics cases, has been opened space for judicial activism. In the theory of the contracts, the formulations of new paradigms, such as equity, good faith and social function authorizes the state intervention in privates business. Especially in the adhesion contracts, in consumer relationships. State intervention, however, have to respect constitutional principles, such warranty of free enterprise, and private property. This article, therefor, through the deductive method, aims to contribute to the considerations of the possibility of states intervention in private educational contracts, reconciling the capitalist model adopted in Federal Constitution order and the guarantees inherent to with the protection of consumers, without this implying as affront to the Federal Constitution limits. To this is necessary to apply the technique of weighing constitutional rights in conflict. The article suggests that State should not intervene in setting private prices, but to facilitate payments.
\end{abstract}

Keywords: Free initiative. Consumer defense. Educacional contract.

\section{INTRODUÇÃO}

A organização normativa do Brasil, baseada em uma Constituição Federal analítica, que consagra a conciliação de princípios aparentemente conflitantes, de modo a sustentar o sistema capitalista de mercado em um Estado 
Social, fez surgir uma espécie de confluência ideológica entre as liberdades privadas e a função pública de seus institutos, mediante a atribuição de uma função social aos contratos, à propriedade e à empresa.

$\mathrm{O}$ advento de um fato extraordinário que implica em redução de capacidade econômica e negocial, como ocorreu com a pandemia advinda da disseminação do vírus SARS-CoV-2, responsável pela COVID-19, cuja velocidade e facilidade de transmissão ensejou a diversos decretos de isolamento social com fechamento de indústrias e comercio, revela-se como fato extraordinário que põe em discussão os métodos adequados à preservação da coexistência de princípios constitucionais, como a livre iniciativa e a defesa do consumidor, nas conflitos de interesse sobre redução de preços privados, como é o caso das mensalidades escolares.

Igualmente, os novos paradigmas da teoria contratual contemporânea, que traz ao lado da autonomia da vontade e da obrigatoriedade a equidade, a boa fé e a função social, inserem uma visão solidarista do contrato. A premissa interpretativa do ordenamento jurídico pátrio é a dignidade da pessoa humana, estabelecida no artigo 10 da Constituição Federal vigente como fundamento da República Federativa do Brasil. Nesse sentido há precedente do Supremo Tribunal Federal informando que a dignidade do ser humano pode ser invocada como fundamento de intervenção estatal nos contratos privados (ADI 319).

Instaurado, portanto, um conflito aparente de princípios constitucionais, o presente artigo se vale do método dedutivo, de pesquisa bibliográfica e análise jurisprudencial, para auxiliar, de modo técnico, a definição das premissas necessárias à legitimação intervenção judicial nos contratos privados, diante de uma Ordem Econômica Constitucional que assegura tanto a livre iniciativa, como a defesa do consumidor.

\section{Da Ordem Econômica Constitucional}

Os princípios gerais que regem a Ordem Econômica Constitucional veem previstos no artigo 170, da Constituição Federal, dentre os quais, para fins de intervenção estatal na definição de preços de mensalidade escolar, destacam-se a livre iniciativa, a justiça social, a propriedade, com sua função social e a defesa do consumidor.
Tem destaque na Constituição Federal a proteção da livre iniciativa, como princípio essência (assim entendidos aqueles que dão sustentação à República Federativa e à Ordem Econômica), uma vez que previsto no artigo 1으, da CF, como fundamento da República, e no caput do artigo 170, da C.F., como fundamento da Ordem Econômica Constitucional.

Como acentuam CANOTILHO (1984), a livre iniciativa comporta um duplo sentido: "Consiste, por um lado, na liberdade de iniciar uma atividade econômica [no caso das Instituições de Ensino Superior (IES) assegurada no art. 209/CF] e, por outro lado, na liberdade de gestão e atividade da empresa" (1984, p. 328). A liberdade de gestão (igualmente assegurada às IES, no art. 207, da Constituição Federal) compreende a definição de preços, dentro da legalidade prevista na lei 9.870/99 (BRASIL, 1999) e a definição da política interna de descontos, ou flexibilização de forma de pagamento. No mesmo sentido arremata Celso Ribeiro Bastos e Ives Gandra Martins:

O seu exercício [da livre
iniciativa] envolve uma
liberdade de mercado, o
que significa dizer que são
proibidos os processos
tendentes a tabelas os
preços ou mesmo a forçar
a sua venda em condições
que não sejam as
resultantes do mercado. A
liberdade de iniciativa
exclui a possibilidade de
um planejamento
vinculante. [...]. Esta
liberdade, como todas as
outras de resto, não pode
ser exercida de forma
absoluta. Há necessidade
de alguns temperamentos.
O importante, contudo, é
notar que a regra é a
liberdade. Qualquer
restrição a esta há de
decorrer da própria
Constituição ou de leis
editadas com fundamento
nela (BASTOS; MARTINS,
1998, p. 16/17).

Ante o exposto é possível fixar a premissa de que intervenção Estatal na economia, para definição de preços e/ou obrigação de concessão de descontos à iniciativa privada, em um Estado 
Democrático de Direito, é exceção autorizada quando expressamente prevista na Constituição Federal e leis com ela compatíveis. Neste sentido, aliás, são os artigos 20, incisos I e III, da lei da liberdade econômica, lei 13.874/2020 (BRASIL, $2020)^{1}$, e o parágrafo único, do artigo 421 , do código Civil².

Alerta Paulo Bonavides que se deve conter a interferência desmedida do Estado na economia, pois, na medida em que ele aumenta seu domínio e interferência, suprimindo ou dificultando a iniciativa privada, estaremos diante de uma transição mais séria e grave, que seria a passagem do Estado Social ao Estado Socialista (BONAVIDES, 2009, p. 186). "Dizem alguns pensadores que a força que acabará com o Estado social é a mesma que o criou: a força das massas", tal qual ocorreu com "[...] Lênin e Sorel no socialismo; Pareto e Mussolini no fascismo; Gobineau, Rosemberg e Hitler no racismo" (op. cit. p. 191/192).

É nítida a opção constitucional pelo modelo capitalista de mercado, ao elencar os princípios da livre iniciativa, a livre concorrência e a propriedade privada. Outrossim, são objetivos da República Federativa do Brasil o desenvolvimento nacional e a erradicação da pobreza (artigo 30, incisos II e III, CF), de modo que a livre iniciativa é essencial à manutenção da ordem constitucional. Paulo Roberto Pereira de Souza, no entanto, adverte que na década de 70 , do século passado, conhecida por milagre brasileiro, ante a evolução econômica do Brasil, não houve redução dos níveis de desigualdade socioeconômicas, mantendo o país no subdesenvolvimento social (SOUZA, 1995, p. 163).

Foi necessário, portanto, visando a evitar os equívocos do capitalismo dos séculos XIX e início do XX, aliar aos princípios da livre iniciativa e da propriedade privada a defesa do consumidor e a função social da propriedade e do contrato. Nota-se que o princípio da unidade da constituição impõe a coexistência das normas constitucionais. Coexistir significa existir em

\footnotetext{
${ }^{1}$ Art. 2ㅇ São princípios que norteiam o disposto nesta Lei:

I - a liberdade como uma garantia no exercício de atividades econômicas;

[...]

III - a intervenção subsidiária e excepcional do Estado sobre o exercício de atividades econômicas; e

${ }^{2}$ Art. 421.[...]

Parágrafo único. Nas relações contratuais privadas, prevalecerão o princípio da intervenção mínima e a excepcionalidade da revisão contratual
}

conjunto, de modo que a observância de uma não pode levar ao esvaziamento do outro, sob pena de inconstitucionalidade.

Não obstante, além de atribuir função social aos institutos capitalistas, o artigo 170 , da Constituição Federal, disciplina a Ordem Econômica também sobre direitos transindividuais, como a defesa do consumidor. A Constituição Federal, portanto, impõe ao Poder Público não só o dever de proteger a Sociedade do Estado, garantindo a propriedade e a livre iniciativa, mas também incumbe ao Poder Público a proteção da Sociedade em face da própria Sociedade. Nesse sentido se viabiliza o dirigismo judicial nos contratos, desde que nos limites da Constituição Federal e da legalidade.

\section{Dos Novos Paradigmas Contratuais}

Partindo da concepção de Savigny, de ser o contrato a união de dois ou mais indivíduos para uma manifestação de vontade em consenso, a teoria clássica assentou as bases do estudo do contrato na autonomia da vontade. A justificativa era simples: Os homens são capazes de regular suas relações de acordo com seus interesses e da melhor forma que Ihes convir, porque são livres e, assim, seriam os melhores juízes de seus interesses (GUILHERME, 2004, p. 34). Desnecessário qualquer esforço para se constatar que a teoria contratual clássica é típica do modelo liberal de Estado.

O liberalismo, contudo, pressupunha um mercado concorrencial perfeito, que na prática não existiu. Suas imperfeições, “[...] bem evidenciadas na passagem do século XIX para o século $X X$ e nas primeiras décadas deste último, associadas à incapacidade de autorregulação dos mercados, conduziram à atribuição de novas funções ao Estado" (GRAU, 2010, p. 19/20). As críticas marxistas ${ }^{3}$, aliadas à crise econômica de 1929, demonstraram ao mundo que o mercado não estava apto a fornecer respostas em tempos de crise. Igualmente, a dinamicidade das mudanças sociais e, sobretudo, a massificação das relações culminaram para a superação da ideia de fundamentar a segurança jurídica na livre manifestação indivíduos. Diante da nova

\footnotetext{
${ }^{3}$ Karl Marx criticou duramente o capitalismo e defendeu um Estado intervencionista, demonstrando que no capitalismo tudo era tratado como mercadoria, inclusive a força de trabalho. Defendeu que o liberalismo só interessava ao capitalista, que se apropriava do excedente produzido pelo trabalhador (mais valia), sem a devida contraprestação (vide: ARAÚJO, C.R.V. História do pensamento econômico: uma abordagem introdutória, São Paulo: Atlas, 1988, p. $58 / 60)$.
} 
realidade não havia mais como se sustentar a autonomia da vontade como justiça do pacto. Por exemplo, no contrato de adesão não há formação negociada do pacto ${ }^{4}$.

A disparidade do poder das partes, diante da massificação de produção e consumo, portanto, fez com que o contrato fosse cada vez mais manipulado, cada vez mais dirigido.

Sobreveio, então, que a mudança de paradigma econômico e o advento do Estado Social fizeram surgir o neoconstitucionalismo, de modo que, conforme demonstrado, ao Estado não cabe mais abster-se da realidade, mas sim apaziguar os conflitos, buscando a dignidade da pessoa humana e o equilíbrio social.

Assim, para se adequar ao neoconstitucionalismo a teoria contratual contemporânea buscou influência na teoria do negócio jurídico e se renovou, mediante a adoção de regras gerais e abstratas, baseadas em princípios que prezam pela segurança do negócio celebrado a partir da tutela da confiança, como a boa fé, a função social e a equidade. Consequência dos novos paradigmas apontados, Cláudia Lima Marques leciona que o contrato de consumo se tornou ponto de encontro de direitos individuais constitucionais, em face dos princípios da igualdade e da dignidade da pessoa humana, haja vista que a disposição constitucional de defesa do consumidor e a consequente visão social e teleológica do contrato como instrumento de expectativas legítimas (MARQUES, 2005, p. 256/257).

Os novos paradigmas da teoria contratual, no entanto, não servem de lacuna aberta ao ativismo judicial imotivado nas relações privadas, mas devem ser amparadas e resolvidas, caso a caso, nos estritos limites impostos pela Ordem Econômica Constitucional e pelas leis vigentes.

\section{Da intervenção Estatal na definição dos preços de mensalidades escolares:}

A intervenção Estatal na economia é medida excepcional, porém justificada, desde dentro dos limites da legalidade e em observância aos princípios e garantias constitucionais. O Estado atua na economia tanto

\footnotetext{
${ }^{4}$ Muitas vezes o indivíduo não tem sequer liberdade para escolher se contrata ou não, como, por exemplo, quando precisa pleitear a ligação de energia elétrica do seu imóvel. Não há, portanto, liberdade de contratar, tampouco de como fazê-lo: simplesmente se adere ao contrato previamente estipulado pelo prestador de serviços.
}

de forma direta, por absorção, ou participação, como de forma indireta, por direção, indução, ou dirigismo (legal, ou judicial).

A fixação de preço escolar tem regulação por lei própria. O dirigismo legal, portanto, na definição dos preços de mensalidades escolares, se dá por meio da lei n.o 9.870/99 (BRASIL, 1999), que em seu artigo 1ㅇ, § 3 , dispõe que o valor da anuidade escolar é deliberado pela instituição de ensino, que pode majorar, a cada ano, desde que proporcionalmente à variação de custos a título de pessoal e de custeio do ano anterior, em relação ao que the precedeu. Assim, o critério material previsto em lei para se cogitar dirigismo judicial em mensalidade escolar é a análise da variação dos gastos operacionais e de investimentos no curso, nos dois anos anteriores ao no letivo que se inicia.

Vale ressaltar que ignorar os limites da legalidade e agir de forma casuísta além de afrontar as bases do Estado Democrático de Direito já se revelou desastroso: Quando da edição da Medida Provisória - MPV n. 579/2012 (BRASIL, 2012), o Governo Federal impôs uma redução na tarifa de energia elétrica, mediante indenização às transmissoras que cumprissem os termos da aludida MPV. A intervenção estatal nos preços gerou enormes prejuízos ao setor, cujos reflexos da desastrada intervenção foram por anos sentidos pelos consumidores. $O$ governo não conseguiu pagar as indenizações e cerca de R\$ 62,2 bilhões foram repassados para pagamento pelos próprios consumidores, mediante aumento na tarifa de energia (SÁ, 2017). O Tribunal de Contas da União concluiu que a "Energia só ficou cara após medida de Dilma para reduzir preço" (AMORA, 2016).

A intervenção estatal no preço das mensalidades escolares é tema sensível. O ensino superior é instrumento da Ordem Social (está inserido no Título VIII, da Constituição Federal), pois visa à existência digna. Visa ele [o ensino] a erradicar o analfabetismo, a valorizar a cultura, a capacitar os brasileiros para o trabalho e à promoção humanística, científica e tecnológica do País (art. 214, CF), contribuindo com os objetivos fundamentais da República Federativa do Brasil, de garantir o desenvolvimento nacional e erradicar a pobreza, a marginalização e reduzir desigualdades sociais (art. 3으, incisos II e III, CF). Tem-se, portanto, que qualquer risco de inviabilizar o ensino superior privado, ainda que parcialmente, deve ser de pronto repelido pelo 
judiciário, sob pena de afronta ao sistema Constitucional brasileiro.

Pesquisa do Instituto SEMESP (2020), feita com base em amostra de 186 instituições de ensino superior - IES no início da pandemia advinda da COVID-19, demonstrou que no Estado de São Paulo houve um aumento de $71,1 \%$, na taxa de inadimplência e de $11,5 \%$, na taxa de evasão escolar, na comparação entre abril de 2019 e abril de 2020 (apud CHIARA, 2020). Em estudo ampliado, do mesmo instituto, com 1257 instituições de ensino superior de todo o país, foi revelado um cenário financeiro catastrófico, no sentido de que um desconto horizontal de $30 \%$ no preço das mensalidades escolares levará cerca de $30 \%$ das instituições de ensino superior a fechar as portas, ainda no ano 2020 (SEMESP, 2020). A previsão não parece ser superestimada: A elevação da inadimplência e a evasão escolar ocorridas no corrente ano (2020) já levou a ASBI - Associação Sociedade Brasileira de Instrução, mantenedora da Universidade Cândido Mendes, a formular e ter deferido pedido de recuperação judicial, em razão da situação de insolvência ocorrida no início do ano de 2020, como consequência da pandemia COVID-19 (RIO DE JANEIRO, 2020). A intervenção judicial para redução de mensalidades escolares, portanto, deve ser a última ratio.

A jurisprudência do Supremo Tribunal Federal considera que a "fixação de preços em valores abaixo da realidade e em desconformidade com a legislação aplicável ao setor configura empecilho livre exercício da atividade econômica, com desrespeito ao princípio da livre-iniciativa" ${ }^{5}$ e, portanto, inconstitucional.

No julgamento da ADI 4.008, o Supremo Tribunal Federal sedimentou o entendimento de que "A interferência estatal na fixação de um preço privado, salvo circunstâncias excepcionais, significa intromissão inadequada no princípio da livre-iniciativa". Os precedentes do Supremo Tribunal Federal, portanto, convalidam a premissa fixada nesse trabalho, de que 0 dirigismo judicial, para definição de preços nos contratos privados, é medida excepcional.

Ocorre que embora a ADI 4008 tenha fixado entendimento de que a intervenção estatal na fixação de preços privados é inconstitucional, o julgado ressalvou

5 BRASIL, STF, Recurso Extraordinário 422.941, rel. Min. Carlos Velloso, DJ 24.03.2006. "circunstâncias excepcionais", como autorizadora do dirigismo judicial. Não há dúvida de que a pandemia advinda do coronavírus se revela como circunstância excepcional. Há que se definir, portanto, em qual grau e circunstâncias as "medidas excepcionais" autorizam o dirigismo judicial na imposição de redução de valor de mensalidades escolares, diante de critérios técnicos legais.

Corolário da isonomia e consequência da equidade, a sinalagma contratual ganha relevância, como preponderante à manutenção das condições do contrato. Equidade se relaciona com a isonomia substancial. Remete à justiça no caso concreto, tratando igualmente os iguais comparação - e desigualmente os desiguais (crianças, idosos, deficientes, consumidores, etc.) - substanciação. A equidade autoriza o dirigismo judicial, visando ao reestabelecimento da sinalagma contratual. Esclarece José Lourenço:

Além das restrições
oriundas da
imperatividader das
normas jurídicas, há
também os limites à
autonomia da vontade
oriundos do fenômeno do
dirigismo contratual, ou
seja, a intervenção estatal
na economia dos negócios
de qualquer espécie. O
dirigismo subentende que,
se os contratantes
pactuassem os negócios
jurídicos com total
liberdade, sem que o
poder estatal pudesse
intervir para mitigar o
princípio pacta sun
servanda- mesmo quando
uma das partes ficasse em
completa ruína - a ordem
jurídica estaria
assegurando apenas a
igualdade perante a lei
(LOURENçO, 2001, p. 20.).

Outrossim, dispõe o Código Civil que

Art. 478. Nos contratos de execução continuada ou diferida, se a prestação de uma das partes se tornar excessivamente onerosa, com extrema vantagem para a outra, em virtude de acontecimentos extraordinários de

\section{s.}


Há, portando, dificuldade prática na aplicação da teoria da imprevisão e da onerosidade excessiva aos contratos educacionais. Isso porque a maior parte dos estabelecimentos de ensino permaneceram cumprindo com a prestação dos serviços, embora tenham o feito por meios remotos de tecnologia de informação, nos termos das Portarias n.os 343, 345 e 544, todas de 2020, editadas pelo Ministério da Educação. Tais Portarias Normativas tornaram a substituição das aulas presenciais por remotas como exercício regular de um direito reconhecido às instituições de ensino.

Conforme exposto, a revisão contratual deve se amparar não só no empobrecimento do consumidor, mas também no aumento do lucro da instituição de ensino. Sem isso, quando houver continuidade da prestação dos serviços, não há desproporcionalidade. O Ministério da Justiça, por meio da Secretaria Nacional de Defesa do Consumidor, destacou, na Nota Técnica 14/2020/CGEMM/DPDC/SENACON/MJ (BRASIL, 2020), ser “[...] evidente que não é cabível a redução de valor das mensalidades, nem a postergação de seu pagamento", durante a pandemia COVID-19, nos casos em que há a continuidade da prestação dos serviços educacionais, com qualidade equivalente, ou semelhante à contratada e respeitada a carga horária mínima e o cumprimento do conteúdo estabelecido na grade curricular, nos casos em que for compatível a substituição das aulas presenciais pelas atividades remotas, ou, quando incompatível, houver oferta de reposição das aulas em período posterior.

A aludida Nota Técnica, no entanto, não põe fim aos conflitos de interesses. Não há solução linear. A solução dos conflitos de interesses envolvendo pretensão de redução de preço de mensalidade escolar deve ser obtida por autocomposição, ou ponderação. Todos os conflitos de interesse exigem diálogo para a consumação de um acordo, entre escolas e consumidores, alicerçado nos princípios da razoabilidade, proporcionalidade e na boa-fé subjetiva. $O$ jurista deve ter em mente que as cortes judiciais não constituem a única forma de solução de conflitos, existindo alternativas para a resolução de controvérsias (CAPPELLETTI; GARTH, 2002, p. 3 a 5). Com efeito, nosso ordenamento jurídico cada vez mais privilegia a autocomposição. Desde a edição da Resolução n.
125/2010, do Conselho Nacional de Justiça, buscou-se introduzir no Brasil o Sistema Multiportas de Solução de Conflitos, o que se tornou definitivo com o advento do Código de Processo Civil de 2015, que estimula a conciliação e a mediação, como métodos eficazes de resolução de conflitos. No entanto, não obtida a autocomposição e ajuizada a lide, ante o princípio da inafastabilidade da jurisdição o conflito deve ser resolvido pelo magistrado, mediante a técnica da ponderação.

\section{Da Técnica da Ponderação}

A dogmática jurídica tradicional, de resolução de antinomia jurídica pelos critérios gramatical, histórico, sistemático e teleológico, por vezes não traz a solução quando se está diante de aparente conflito de direitos constitucionais. $O$ dirigismo judicial, para redução de valor de mensalidade escolar, se situa justamente no aparente conflito dos direitos constitucionais da livre iniciativa com a defesa do consumidor.

\section{Enfatiza Luís Roberto Barroso que}

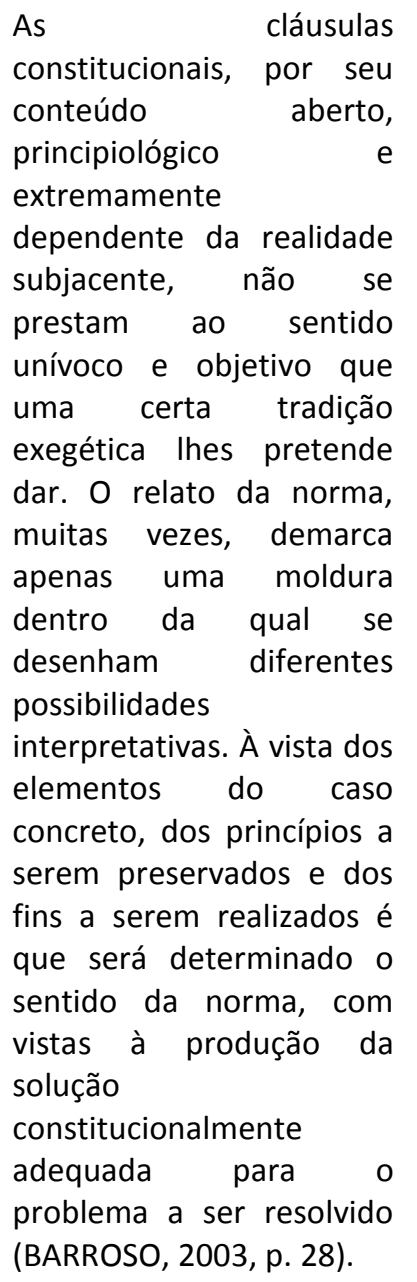




\section{Prossegue o citado doutrinador enfatizando que}

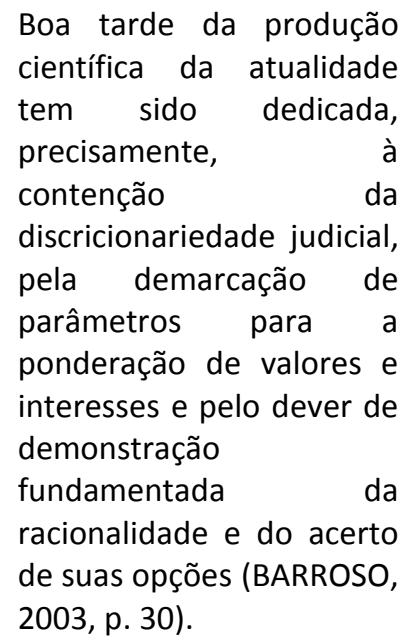

Extrai-se da doutrina, portanto, que não se pode almejar prevalecer um dos direitos constitucionais em aparente conflito, com base em conclusões genéricas e predeterminadas. Não se deve, por exemplo, defender a prevalência da defesa do consumidor em detrimento da livre iniciativa, sob o argumento de se tratar de direito transindividual, da mesma forma que é descabido o argumento de prevalência da livre iniciativa, sobre a defesa do consumidor, por ser base de sustentação da República Federativa do Brasil e da Ordem Econômica Constitucional, figurando tanto no artigo 10, como no caput do art. 170, ambos da Constituição Federal.

Segundo as ideias de Dworkin e Alexy, enquanto as regras veiculam mandados de definição (ou são válidas e se aplicam, ou não se aplicam, por inválidas), os princípios veiculam mandados de otimização, na medida em que admitem aplicação mais ou menos intensa de acordo com as particularidades do caso concreto, sem que a aplicação de um comprometa a validade e aplicação de outro, de mesma estatura, como se houvesse hierarquia entre eles (apud BARROSO, 2003, p. 37).

O dirigismo judicial em preço de mensalidade escolar, portanto, reclama a ponderação dos princípios constitucionais da livre iniciativa e da defesa do consumidor, diante de cada caso concreto. A ponderação reclama um raciocínio complexo sobre os fatos, sopesando os interesses, os bens, os valores e as normas. Luís Roberto Barroso descreve que a ponderação reclama três etapas (BARROSO, 2003, p. 40/41):

- Primeira: Detectar as normas relevantes para a solução do caso (as premissas maiores, da atividade silogística), identificando eventuais conflitos entre elas;

- Segunda: Examinar os fatos do caso concreto e sua interação com os elementos normativos, ou seja, identificar a norma jurídica do caso concreto ao preencher o conteúdo abstrato dos princípios, dando maior clareza ao papel que cada um deles influencia no caso;

- Terceira (e que diferencia a ponderação da subsunção): exame dos diferentes grupos de normas jurídicas do caso concreto identificados na segunda fase, de forma conjunta, para avaliar os pesos que devem ser atribuídos a cada um dos elementos em disputa, no intuito de realizar a escolha fundamentada de qual deles deve preponderar diante do caso concreto, graduando a sua intensidade, sempre com base no princípio instrumental da proporcionalidade ou razoabilidade.

A ponderação, no entanto, embora necessária à solução dos chamados casos complexos (assim entendidos aqueles não resolvidos por subsunção), não é imune de críticas, havendo quem sustente se tratar de um subprincípio do princípio da proporcionalidade (ALEXY, 2003, p. 136). Descabida, no entanto, a crítica, na medida em que a ponderação impõe ao magistrado a necessidade de exposição das normas jurídicas do caso concreto e indicação dos fatores relevantes de referências materiais para a escolha adotada. Não se trata a ponderação de escolha filosófica ou ideológica, mas de técnica de interpretação constitucional. Deve haver motivação judicia devidamente expressa, na fundamentação da decisão judicial, nos termos do artigo 489, §§ $1^{\circ}$ e 2으, do Código de Processo Civil, para que o jurisdicionado possa fazer o controle de legalidade, por meio do recurso cabível, caso a escolha do magistrado não seja técnica.

O Tribunal de Justiça do Estado de São Paulo, por exemplo, negou provimento a um recurso de agravo de instrumento que visava a reforma da decisão que indeferiu o pedido de desconto na mensalidade escolar, em decorrência de suposto desequilíbrio na relação contratual, em razão da Pandemia de Covid-19 (SÃO PAULO, 2020). A recorrente fundamentou que em razão do não oferecimento de atividades presenciais a escola frequentada pelo seu filho, 
matriculado para o período integral, teria seus custos reduzidos pela ausência dos alunos em relação à água, energia e alimentação, razão pela qual deveria reajustar o valor da mensalidade escolar, além de ter sido atingida em termos econômicos, pelas quarentenas instituídas pelo Governo Estadual, aplicando-se, portanto, em tese, a teoria da onerosidade excessiva, como autorizadora do dirigismo judicial para a revisão do contrato. O Juízo, no entanto, entendeu que apesar da situação superveniente, a escola estava buscando métodos de adaptação alternativos para repor as aulas contratadas e que não é de controle da instituição a impossibilidade de aulas presenciais, nos moldes convencionados originalmente. Prevaleceu, no caso, o entendimento que o modo de transmissão online é uma necessidade que beneficia o bem estar coletivo para atender aos cuidados com a saúde e ocorre por motivos evidentemente estranhos à vontade de ambas as partes, porém, ainda assim, gera custos devido à adaptação de estrutura e manutenção do corpo docente. Ressaltou ainda a observância dos princípios norteadores do Direito Contratual, como o princípio da boa-fé objetiva juntamente com os deveres inerentes ao mesmo. Houve, portanto, a ponderação do direito do consumidor em relação às medidas de prevenção à saúde, face ao contágio que a aglomeração em salas de aula pode gerar, sendo inviável o reestabelecimento do atendimento presencial contratado. Se o meio remoto das aulas compromete ou não a qualidade do ensino, podendo caracterizar vício na qualidade do serviço, é matéria probatória a ser demonstrado no caso concreto.

Sendo assim a adaptação acontece de forma mútua, havendo dois pontos a serem avaliados: o pagamento referente à mensalidade escolar, com pedido de extinção temporária ou redução, e os custos de existência do curso, ou da entidade, com a margem de lucro contratada antes da circunstância excepcional, para garantia a subsistência de seu negócio.

\section{CONCLUSÃO}

A manutenção das escolas é um interesse social e serviço essencial. Trata-se, a relação entre aluno e escola, de contrato consumerista que exige consenso como uma via de mão dupla, contemplando a todos os interesses. $O$ desconto na mensalidade é recomendável às instituições de ensino, em situações excepcionais, como é o caso da pandemia advinda da COVID-19, mas por meios alternativos de solução de conflitos e não por imposição estatal, a em regra. Assim, há apreço pela aplicação concreta do princípio da boa-fé, da cooperação e da lealdade em razão da importância da manutenção das Escolas pelo serviço educacional que presta, e também atendendo a função social do contrato oferecido.

Não obtida a conciliação estar-se-á diante de uma lide que põe em conflito a propriedade privada e a livre iniciativa ante a defesa do consumidor e a teoria finalística dos contratos. A rescisão do contrato é assegurada a qualquer aluno que a deseje, sem aplicação de penalidades, haja vista a aplicação do disposto no artigo 393, do Código Civil, que prevê o caso fortuito e a força maior como excludentes de responsabilidade. A pandemia e os decretos governamentais de quarentena, advindos da COVID-19, são típicos exemplos de força maior e caso fortuito. Não sendo a rescisão do contrato a opção do discente, as circunstâncias excepcionais da pandemia advinda da COVID-19 abrem a oportunidade para o dirigismo judicial dos contratos de prestação de serviços educacionais, seja diante da teoria da imprevisão, seja por força de onerosidade excessiva. A solução, no entanto não é fácil, pois em se tratando de conflito de normas constitucionais impõe-se a adoção da técnica de ponderação.

Identificadas as normas constitucionais que regulam o caso (primeira etapa), passa-se a examinar os fatos do caso concreto diante dos princípios constitucionais que incidem (segunda etapa). Por fim, deve se fazer o cotejo das normas jurídicas do caso concreto, para diante da razoabilidade e da proporcionalidade optar pela solução que coaduna com o ordenamento jurídico vigente. Assim, a técnica da ponderação, no caso de definição judicial de preço de mensalidade escolar, impõe a análise efetiva do grau de comprometimento financeiro do grupo familiar do aluno, que invoca a onerosidade excessiva como causa de pedir de sua pretensão, em cotejo com a demonstração de vantagem econômica para a instituição de ensino, na substituição das aulas presenciais por remotas.

A redução da capacidade financeira do consumidor deve ter nexo de causalidade com a pandemia. Só ela, no entanto, não autoriza o dirigismo judicial na definição de preço privado, haja vista que a equidade pressupõe a sinalágma contratual. Assim, tanto a imprevisão, como a onerosidade excessiva pressupõem o desequilíbrio contratual, como requisito da 
intervenção estatal no contrato. Tais teorias não visam a um benefício gracioso ao consumidor, mas sim a reestabelecer o equilíbrio econômicofinanceiro do contrato, razão pela qual é imprescindível que a substituição do modo de oferta das aulas tenha gerado redução de custos para a instituição de ensino, que consequentemente Ihe traga aumento no percentual de lucro embutido no preço da mensalidade. Sem isso não há o requisito do desequilíbrio do contrato, inviabilizando a ação revisional.

Por fim, não optando o consumidor pela rescisão do contrato e não havendo desequilíbrio contratual, a intervenção judicial deve se restringir a viabilizar a continuidade do contrato de prestação de serviços educacionais, uma vez se tratar de contrato de prestação continuada, sem redução de preço, mas impondo meios de flexibilização de pagamento, tais como prorrogação do vencimento das obrigações, parcelamento, etc. $O$ contrato constitui ato jurídico perfeito, logo a revisão, para fins de redução de preço de mensalidade escolar, como medida excepcional que é, deve se amparar nas peculiaridades do caso concreto que demonstre que as circunstâncias excepcionais advindas da pandemia trouxeram desequilíbrio à relação jurídica, devendo ele ser o contrato dirigido pelo Poder Judiciário, de forma a reestabelecer as condições econômicas-financeiras anteriores ao evento externo.

\section{REFERÊNCIAS}

ALEXY, Robert. Constitutional rights, balancing, and rationality. In: Ratio Juris, v. 16, n. 2, june, $2003 . \quad$ Disponível em: https://onlinelibrary.wiley.com/doi/epdf/10.1111 /1467-9337.00228. Acesso em: 17 ago. 2020. DOI https://doi.org/10.1111/1467-9337.00228.

AMORA, Dimmi. Energia só ficou cara após medida de Dilma para reduzir preço, diz TCU. In: Folha de S. Paulo, 17 ago. 2016. Disponível em: https://www1.folha.uol.com.br/mercado/2016/1 0/1826549-energia-so-ficou-cara-apos-medidade-dilma-para-reduzir-preco-diz-tcu.shtml. Acesso em: 17 ago. 2020.

BARROSO, Luís Roberto. O Começo da História: A nova interpretação constitucional e o papel dos princípios no Direito brasileiro. In: Revista EMERJ, v. 6, n. 23, 2003.
BONAVIDES, Paulo. Do Estado Liberal ao Estado Social. 9. ed. São Paulo: Malheiros, 2009.

BRASIL. Constituição (1988). Constituição da República Federativa do Brasil. Brasília: Senado Federal, 1988.

BRASIL. Presidência da República. Lei n.o 9.870, de 23 de novembro de 1999. Dispõe sobre o valor total das anuidades escolares e dá outras providências. Brasília, 1999. Disponível em: http://www.planalto.gov.br/ccivil_03/leis/19870. htm. Acesso em: 17 ago. 2020.

BRASIL. Presidência da República. Lei n.o 13.784, de 20 de setembro de 2019. Disponível em: http://www.planalto.gov.br/ccivil_03/_ato20192022/2019/lei/L13874.htm. Acesso em: 17 ago. 2020.

BRASIL. Câmara dos Deputados. Medida Provisória n.o 579, de 11 de setembro de 2012. Disponível em: https://www2.camara.leg.br/legin/fed/medpro/2 012/medidaprovisoria-579-11-setembro-2012774153-norma-pe.html. Acesso em: 17 ago. 2020. . Ministério da Justiça e da Segurança Pública, Nota Técnica n.으 14/2020/CGEMM/DPDC/SENACON/MJ. Disponível em: https://www.mprs.mp.br/media/areas/covid/arq uivos/outros/mjsp_senacon_nt_14.pdf. Acesso 17 ago. 2020.

- Supremo Tribunal Federal, Ação Direta de Inconstitucionalidade n.o 319., Rel. Min. Moreira Alves, DJ 30.04.1993. Disponível em: https://redir.stf.jus.br/paginadorpub/paginador.j sp?docTP=AC\&docID=918. Acesso 17 ago. 2020.

- Supremo Tribunal Federal, Ação Direta de Inconstitucionalidade n.o 1081., Rel. Min. Francisco Rezek, DJ 03.12.1999. Disponível em:

https://redir.stf.jus.br/paginadorpub/paginador.j $s p$ ?docTP=AC\&doc $I D=346813$. Acesso em: 17 ago. 2020.

Supremo Tribunal Federal, Ação Direta de Inconstitucionalidade n.o 1007., Rel. Min. Eros Grau, DJ 24.02.2006. Disponível em: https://redir.stf.jus.br/paginadorpub/paginador.j 
sp?docTP=AC\&docID=266615. Acesso 17 ago. 2020.

CANOTILHO, Vital Moreira. Constituição da República Portuguesa Anotada. 2. ed. Coimbra: Editora Coimbra, 1984. p. 328, v.1 .

CAPPELLETTI, Mauro; GARTH, Bryant. Acesso à justiça. Porto Alegre: Fabris, 2002.

CHIARA, Márcia de. Inadimplência no Ensino Superior de SP cresce mais de 70\% em abril. In: 0 Estadão, 17 abr. 2020. Disponível em: https://educacao.estadao.com.br/noticias/geral,i nadimplencia-no-ensino-superior-de-sp-crescemais-de-70-em-abril,70003274524. Acesso em: 18 ago. 2020.

BASTOS, Celso Ribeiro; MARTINS, Ives Gandra. Comentários à Constituição do Brasil. São Paulo: Saraiva, 1998, p. 16, 17, v.7.

GUILHERME, Luiz Fernando de Almeida. Contribuições ao Estudo do Novo Direito Civil, Campinas: Millennium, 2004.

GRAU, Eros. A Ordem Econômica na Constituição de 1988. 14. ed. São Paulo: Malheiros, 2010.

LOURENÇO, José. Limites à Liberdade de Contratar. São Paulo: Editora Juarez de Oliveira, 2001.

MARQUES, Cláudia Lima. Contratos no Código de Defesa do Consumidor: o novo regime das relações contratuais. 5. ed. São Paulo: Revista dos Tribunais, 2005.

NERY, Rosa Maria de Andrade; NERY JR., Nelson. Instituições de Direito Civil: Das obrigações, dos contratos e da responsabilidade civil. 2. ed., São Paulo: Thomson Reuters Brasil, 2019.

RIO DE JANEIRO (Estado). Tribunal de Justiça do Rio de Janeiro, Processo n. 009375490.2020.8.19.0001, juiz Maria da Penha Nobre Mauro, decisão de 17 mai. 2020. Disponível em: http://www4.tjrj.jus.br/consultaProcessoWebV2/ consultaProc.do?v=2\&numProcesso $=2020.001 .07$ 1841-

8\&FLAGNOME=S\&tipoConsulta=publica\&back=1 \&PORTAL=1\&v=2. Acesso 20 ago. 2020.

SÁ, Rachel de. O aumento da conta de luz e os fantasmas do governo Dilma que ainda assombram nosso presente. In: INFOMONEY, 07 mar. 2017. Disponível em: https://www.infomoney.com.br/colunistas/terra co-economico/o-aumento-da-conta-de-luz-e-osfantasmas-do-governo-dilma-que-aindaassombram-nosso-presente/. Acesso 17 ago. 2020.

SÃO PAULO. Tribunal de Justiça do Estado de São Paulo, Agravo de Instrumento n. 206376780.2020.8.26.0000, Relator: Edgard Rosa, Data de Julgamento: 14/04/2020, 22a Câmera de Direito Privado, Data de Publicação: 14/04/2020. Disponível em: https://tjsp.jusbrasil.com.br/jurisprudencia/831979177/ag ravo-de-instrumento-ai-20637678020208260000sp-2063767-8020208260000/inteiro-teor-

831979197 ?ref=juris-tabs. Acesso em 20 ago. 2020.

SEMESP. Secretaria de Modalidades Especializadas de Educação. Posicionamento oficial do SEMESP sobre a redução do valor das mensalidades. 2020. Disponível em: https://www.semesp.org.br/noticias/posicionam ento-oficial-do-semesp-sobre-a-reducao-dovalor-das-mensalidades/. Acesso 18 ago. 2020.

SOUZA, Paulo Roberto Pereira de; MILLS, Jon. (coord.). Conflitos Jurídicos Econômicos e Ambientais - Estratégias para o desenvolvimento de políticas ambientais e de uso do solo: um estudo de caso da Flórida (EUA) e Paraná (Brasil), Maringá: EDUEM, 1995. 